\title{
THE CASE FOR CONSENT PLURALISM
}

\author{
Jessica Keiser
}

()$^{N}$

$\mathrm{N}$ THE CREST of the \#MeToo movement, a campaign aimed at spreading awareness about the global culture of sexual harassment and assault, website Babe.net published a story in which an anonymous woman detailed her date with comedian and self-proclaimed feminist ally Aziz Ansari. Under the pseudonym "Grace," she described an evening in which Ansari disregarded her repeated attempts to communicate discomfort with his sexual advances, calling it "the worst night of [her] life" as well as an experience she has come to recognize as "sexual assault." The flurry of public response involved a number of high-profile op-eds in journals, including The Atlantic and The New York Times, that decried what they saw as the passive self-victimization of Grace and the overreach of the \#MeToo movement. Others, in contrast, argued that Grace's all-too-familiar experience highlights the need for radical change in our conventions and conversations involving consent.

Some of the key issues emerging within public discourse in the wake of the Ansari scandal reflect a long-standing philosophical debate about the nature of consent-in particular, whether consent is best construed as a type of mental state or a form of behavior. For instance, some disputes over the status of Ansari's actions seem to hinge on whether Grace's preferences and attitudes are taken to determine her consent, or rather her behavioral cues about these mental states - and, if the latter, which types of cues are taken to be relevant. The last few decades have seen a deepening divide over this question among philosophers and legal theorists, which is now unfolding in the broader public spherebut until there is some sort of convergence on what kind of thing consent is, we cannot hope to understand the mechanism behind its peculiar power to alter the normative landscape, nor to have a principled basis on which to form moral decisions and social policies.

I argue that the impasse in the debate over the ontology of consent is owed to the fact that prominent accounts on all sides have gotten something crucially right while sharing a common flawed methodological assumption. They are right in that they each identify something that plays consent's normative role; they are 
wrong, however, in their shared assumption that there is one thing that does so uniquely or essentially. Rather, this role is played by both mental states and behavior in independent and context-sensitive ways. ${ }^{1}$ The upshot is that, insofar as we seek to understand consent-based moral transformations, we ought to adopt a pluralistic approach to consent that gives independent weight to the moral contributions of facts about mental states and facts about behavior relative to a context. ${ }^{2}$

Here is the road map: In section 1, I outline consent's normative role-its distinctive power to alter the normative landscape. In section 2, I introduce two competing conceptions of consent-mental consent and behavioral consentshowing that each plays this role and thus neither plays it uniquely. In section 3 , I argue that neither mental consent nor behavioral consent plays this role essentially, given that (1) there are contexts in which mental consent fails to introduce permissions in the absence of behavioral consent, and (2) there are contexts in which behavioral consent fails to introduce permissions in the absence of mental consent. In section 4, I address potential responses. In section 5, I argue that moving to a hybrid account (in which consent requires both behavior and mental states) provides an inadequate solution, as it collapses the complex normative structure arising from two distinct mechanisms for introducing permissions. Section 6 concludes that there is no single type of thing that uniquely or essentially displays consent's peculiar power to alter the normative landscape, and that an adequate theory of consent must adopt a pluralistic approach.

\section{THE NORMATIVE ROLE OF CONSENT}

I will begin by considering what a theory of consent aims to do. As in any other domain, theorists may approach this topic from divergent intellectual traditions, and with an eye to varying theoretical questions and practical concerns. ${ }^{3}$ Con-

1 Westen makes a similar point in relation to legal consent; however, he is concerned with legal rather than moral power-specifically, the role of different conceptions of consent within criminal law (The Logic of Consent).

2 Since this paper was written, Dougherty has published an article arguing that violation of mental and behavioral consent ought to be treated as independent offenses for the purposes of legal policy, though he is explicitly neutral on questions of ontology ("Affirmative Consent and Due Diligence"). In contrast, this paper argues that they ought to be treated as independent moral mechanisms for the purpose of developing an ontology of consent; however, because these issues are related, some of the considerations provided in support of this thesis are congenial to Dougherty's arguments about policy making.

3 For instance, some theorists have been interested in consent in relation to political authority (see, e.g., Hobbes, Leviathan; Locke, The Two Treatises of Civil Government; Beran, The Consent Theory of Political Obligation; Estlund, Democratic Authority), others in relation to rape law (see, e.g., MacKinnon, Toward a Feminist Theory of the State; Archard, Sexual Consent; 
sequently, there may be a variety of perspectives regarding the desiderata for a theory of consent. So while I will not presume to identify a unique or privileged characterization of its goals, it will be helpful to say something about how I am approaching the issue.

I adopt a starting assumption that consent displays an identifying characteristic feature: the power to alter the normative landscape. Of course, characterized so broadly, this power is not unique to consent; normative facts are responsive to myriad kinds of occurrences in the world. But consent functions to alter the normative landscape in a distinctive and somewhat puzzling way. First, consent is something that agents do in some important sense, and this is often described in terms of being a manifestation of agency. ${ }^{4}$ We must tread carefully here, however: there are open and controversial issues in the philosophy of agency that are often breezed over when this term is co-opted in the literature on consent. To pack too much into this notion of being a manifestation of agency (stipulating that it must be an action, or that it must be intentional, etc.) would beg the question against certain accounts from the outset; therefore, I assume only that consent is an action/mental state of the consenter, which manifests agency in the sense of being responsive to her reasons and settling certain facts in the world. ${ }^{5}$ Second, consent is intentional in the sense of bearing content-it is about, or directed toward, the act consented to. ${ }^{6}$ Third, consent is other-regarding — by consenting, the consenter alters the duties of another moral agent. Fourth, this alteration involves rendering permissible an action that would have otherwise been impermissible. ${ }^{7}$ The distinctive nature of consent is often contrasted with that of promising. ${ }^{8}$ While

Ferzan, "Consent, Culpability, and the Law of Rape"), and others in relation to medical practice (see, e.g., Faden and Beauchamp, A History and Theory of Informed Consent; Manson and O'Neill, Rethinking Informed Consent in Bioethics).

4 Cf. Pateman, "Women and Consent"; Schulhofer, "The Feminist Challenge in Criminal Law”; Hurd, “The Moral Magic of Consent”; Kleinig, "The Nature of Consent”; West, "Sex, Law, and Consent"; Anderson, "All-American Rape"; Dougherty, "Sex, Lies, and Consent"; Manson, "Permissive Consent."

5 Responsiveness to reasons is standardly taken to be characteristic of moral and epistemic agency. For discussion about how manifestations of agency settle facts in the world, see Steward, A Metaphysics for Freedom.

6 Cf. Hurd, "The Moral Magic of Consent"; Archard, Sexual Consent; Wertheimer, Consent to Sexual Relations; Owens, "The Possibility of Consent"; Dougherty, "Sex, Lies, and Consent”; Alexander, "The Ontology of Consent"; Manson, "Permissive Consent."

7 Cf. Hurd, "The Moral Magic of Consent"; Archard, Sexual Consent; Wertheimer, Consent to Sexual Relations; Westen, The Logic of Consent; Owens, "The Possibility of Consent"; Alexander, "The Ontology of Consent”; Dougherty, "Yes Means Yes”; and Alexander, Hurd, and Westen, "Consent Does Not Require Communication."

8 Cf. Shiffrin, "Promising, Intimate Relationships, and Conventionalism”; Owens, “The Pos- 
both are content-bearing exercises of individual agency, promising introduces an obligation for its performer, while consent introduces a permission for its receiver. Fifth, consent alters the normative landscape via altering the normative relationship between its giver and receiver; it relieves the consentee of a directed duty to refrain from performing a certain action, which is owed to the consenter. Finally, consent removes certain — but not necessarily all—barriers to permission.

There are broadly two classes of cases in which consent may fail to introduce an all-things-considered permission.

1. When there are independent, overriding sources of impermissibility.

How to non-circularly characterize what qualifies as "independent" is a vexed issue that we will return to in section 4 . To get a grip on things for now, we can simply think of independent prohibitions against an agent's performing an action as those grounded in reasons other than the fact that the action would violate the would-be consenter's consent.

2. When consent violation is not prohibited to begin with-either because it does not wrong the would-be consenter (I do not wrong you by failing to obtain your consent to water my houseplants), or because the wrongdoing is justified by independent moral considerations (I am permitted to borrow your car without consent to drive a sick child to the hospital, even if this consent violation wrongs you).

Let us call this second class of cases trivial cases. I will for the most part ignore trivial cases, and the characterization below can be understood as implicitly bracketing them off. I will return to the first class of cases in section $4 .^{9}$

We can think of the property outlined above as consent's normative role:

Normative Role of Consent: Being a content-bearing act/mental state that manifests the consenter's agency and introduces a permission for the consentee (absent independent, overriding sources of impermissibility), thus altering the normative relationship between them. ${ }^{10}$

Though this dialectic is not usually made explicit, debates over the ontology of consent often take the normative role of consent as an anchor or starting point; fit with this role is used to adjudicate between competing accounts. Ontological

sibility of Consent"; and Dougherty, "Fickle Consent" and "Yes Means Yes."

9 Theorists sometimes appeal to the distinction between valid consent-in which consent succeeds in altering the normative landscape-from invalid consent, in which it fails. 
theories of consent typically take for granted that the normative role of consent is its identifying feature and aim to characterize the kind of thing that plays this role; they are justified at least partially to the extent that it succeeds in this task, and criticized at least partially to the extent that they fail to do so. ${ }^{11}$

My approach follows this dialectic in assuming that a primary desideratum of an ontology of consent is to provide an account of kind of thing that plays its normative role. However, I reject a crucial assumption underlying this dialect, which is that there is something that does so uniquely and essentially. ${ }^{12} \mathrm{I}$ argue that both mental consent and behavioral consent play this role, though contingently and for different reasons; insofar as a theory of consent aims to elucidate its normative power, it must take a pluralistic approach that recognizes both mental and behavioral consent as independent and context-sensitive mechanisms for changing the normative landscape.

\section{NON-UNIQUENESS OF NORMATIVE ROLE: TWO CONCEPTIONS OF CONSENT}

In this section I introduce two competing conceptions of consent: mental consent*, which takes consent to be a kind of mental state, and behavioral consent*, which takes consent to be a form of behavior. I include a star to avoid the misleading impression of begging the question by presupposing that either of these conceptions is, in fact, consent-rather, we will treat them as candidates to be evaluated. The central claim of this section is that the normative role of consent does not lie uniquely within the domain of either of these candidates, but is filled by both. I support this claim by showing that there are at least some kinds of mental states and some forms of behavior that play consent's normative role-thus, neither mental states nor behavior do so uniquely.

\subsection{Mental Consent ${ }^{*}$}

According to one prominent position, consent is a kind of attitude or mental state-I will call this mental consent* Adherents of this position will adopt something like the following schema, offering various substitutions for $\psi$ :

11 This approach has much in common with a methodology championed by philosophers, in cluding David Lewis and Frank Jackson, known as the "Canberra Plan," which proceeds in roughly two steps. The first step can be thought of as conceptual analysis: here we identify the theoretical role of the object of inquiry. The metaphysics comes in at the second step: here we seek to identify what kind of thing plays that theoretical role. it was typically assumed that different kinds of things would play the same theoretical role across worlds. 
$A$ mentally consents* to $B$ performing $\phi$ just in case $A$ has mental state $\psi$.

Hurd, for instance, characterizes $\psi$ as the intention for $B$ to perform $\phi$, while Alexander suggests that it is $A$ 's waiving their right to complain about a moral or legal boundary crossing resulting from $B$ 's performing $\phi .{ }^{13}$ Westen describes it as state of mind of acquiescence to $B$ 's performing $\phi .{ }^{14}$

My aim in this section is to establish that there is at least some precisification of this schema (that is, some value of $\psi$ ) such that mental consent ${ }^{*}$ plays consent's normative role. I remain neutral on how best to characterize this mental state (or states); however, I will adopt a simplified toy theory for illustration. This theory is intended to facilitate clarity in the following discussion, rather than as a serious proposal for how to characterize mental consent*. However, if I can show that the mental state used in the toy theory plays the normative role of consent, I will have established that there is at least one mental state that does so. The reader may substitute her preferred characterization of $\psi$; if she agrees that there is some way of filling out the schema such that mental consent* plays consent's normative role-regardless of whether she agrees that the toy theory meets this condition-I will have achieved my aim. I will have failed if the reader doubts that there is any way of filling out the schema that does so.

Here is the toy theory I will adopt:

Mental Consent ${ }^{*}: A$ mentally consents* to $B$ performing $\phi$ just in case $A$ is not opposed to $B$ performing $\phi$.

According to this theory, mental consent* marks a threshold in an agent's preference ordering. Above the threshold are states of affairs to which she consents, including those for which she has a positive preference, as well as those toward which she is merely indifferent. Below are states of affairs to which her preference ordering assigns a sufficiently low value-i.e., those to which she is opposed. One way in which this toy theory may be too simple to serve as a serious characterization of mental consent ${ }^{*}$ is that we might want to allow that agents can prefer things to which they do not consent, and vice versa. Recall, however, that my aim is not to offer a proposal for how mental consent* ought to be defined, but rather to establish that there is at least one mental state that plays consent's normative role.

As noted earlier, we will bracket off trivial cases in which consent fails to introduce permissions because the relevant action is not morally prohibited to begin with. ${ }^{15}$ On this conception of mental consent*, nontrivial cases are those

13 Hurd, "The Moral Magic of Consent"; and Alexander, “The Moral Magic of Consent (II)."

14 Westen, The Logic of Consent.

15 For instance, I may prefer that a stranger not sit in the seat next to me on the bus, but they 
in which performing an act in opposition to another's preferences wrongs them, and the prohibition against this wrongdoing is not overridden by independent moral considerations. I will remain neutral about what grounds the fact that acting in opposition to another agent's preferences wrongs her in some contexts-because such preferences track her welfare, or because doing so would constitute a rights violation, etc.- - but I take it as uncontroversial that this is so. Tellingly, examples can be found in paradigmatic contexts where consent is morally significant, such as sexual activity. West, for instance, suggests a number of potential sources of the "distinctive harm" of unwanted sex:

Such sex is likely to be alienating, and in something like the original sense of that word: it alienates a girl or woman from her own desires and pleasures, and from that sense of unified identity that comes from acting in the world on the basis of one's own desires and pleasures.... And-if it becomes a central part of a life that ties her existence, survival, and hence her interests to that of another-if unwanted sex is the raison d'être for a way of life that limits her mobility, her ambition, and the development of her talents or remunerative skills-it constitutes a threat to her autonomy, likewise. ${ }^{16}$

I will use unwanted sex as a paradigm case of wrongdoing by violating mental consent*; however, readers may substitute a different case if they find it contentious. ${ }^{17}$ The arguments that follow rest only on the assumption that there is at least one mental state $\psi$ and at least some action $\phi$, such that $B$ wrongs $A$ by performing $\phi$ if $A$ fails to have mental state $\psi$. I take it that this holds true when the relevant action is sexual activity with $A$ and the relevant mental state is failure to oppose it, and will proceed with this example in the remainder of the paper-the reader, however, may substitute any mental state $\psi$ and action $\phi$ that she finds convincing.

Because engaging in sexual activity with a person in opposition to their preferences wrongs them (I will set aside issues of blameworthiness and return to them later), $A$ has a directed duty toward $B$ to refrain from engaging in sexual activity with her without her mental consent*. If $A$ gives her mental consent*, she relieves $B$ of this duty, thereby introducing a permission absent independent and overriding sources of prohibition.

are nonetheless permitted to do so. It is notable that mental consent* still plays an important social function even in many trivial cases; it is common for a stranger on the bus to ask "May I?" before sitting down, and there is a general expectation that others will honor our preferences if it comes at no cost to themselves.

West, "Sex, Law, and Consent," 27. 
If the foregoing is correct, mental consent ${ }^{*}$ plays the normative role of consent: it is a manifestation of the consenter's agency in that it is a mental state that is responsive to reasons and settles certain facts in the world—in this case, facts about what is morally permissible for others. (Again, readers preferring a more stringent account of agency can feel free to substitute a different account of mental consent; my argument only depends on there being some mental state that satisfies these conditions.) It is intentional in the sense of bearing content-the relevant preferences are directed toward the act being consented to. It is other regarding in that an agent's mental consent introduces a permission for its receiver absent independent, overriding sources of impermissibility. It alters the normative relationship between the consenter and consentee by relieving the latter of a directed duty owed to the former: the duty to refrain from violating their preferences.

\subsection{Behavioral Consent*}

An alternative view is one that takes consent to be some form of behavior-I will call this behavioral consent* (Again, I add a star to highlight that we are not presupposing that this conception is, in fact, consent.) While few adopt a purely behaviorist view, consideration of this position will serve to map out the logical space before turning to a hybrid account in section 5. Adherents of this position will adopt something like the following schema, offering various substitutions for $\psi$ :

$A$ behaviorally consents* to $B$ performing $\phi$ just in case $A$ performs behavior $\psi$.

Here I argue that there is at least some precisification of this schema (that is, some value of $\psi$ ) such that behavioral consent plays consent's normative role. Again, I will remain neutral on how best to characterize the particular behavior (or behaviors) that constitutes behavioral consent*, but will adopt a working theory for clarity. As before, the reader can feel free to substitute her preferred characterization of $\psi$ in the discussion that follows; as long as the reader agrees that there is some way of filling out the schema such that behavioral consent* plays consent's normative role, I will have achieved my aim.

I will adopt the following toy theory:

Behavioral consent*: $A$ behaviorally consents* to $B$ performing $\phi$ just in case $A$ performs some action that signals to $B$ that she mentally consents* to $B$ performing $\phi$.

We will understand signaling in a rough and ready way, leaving it deliberately unspecific in order to accommodate a range of approaches. This theory characterizes behavioral consent ${ }^{*}$ as an action that functions to provide the consen- 
tee with evidence about the consenter's mental states. We will assume for now that signaling need not be factive; in providing evidence about her mental state, the consenter may be disingenuous or inaccurate. (We will consider hybrid accounts, which may introduce factivity, in due course.)

The last section claimed that there is at least one mental state $\psi$ and at least some action $\phi$, such that $B$ wrongs $A$ by performing $\phi$ if $A$ fails to have mental state $\psi$. If this is so, then performing such actions without sufficient evidence of such mental states puts the would-be consenter at risk of being wronged ${ }^{18}$ It is commonly acknowledged that placing someone at risk of being wronged-regardless of whether that wrong comes to fruition-is morally prohibited when this risk is sufficiently high and there are not overriding moral reasons in favor of performing the action. For instance, it is morally prohibited to randomly fire shots into a crowd regardless of whether anyone gets hit, and it is morally prohibited to blow up a building without knowing whether it is occupied, regardless of whether it turns out to be empty; many, including Jackson and Zimmerman, have emphasized that an adequate moral theory must accommodate such facts. ${ }^{19}$ As Zimmerman points out, one may do so using a variety of moral frameworks, whether they take moral permissibility to be determined by "objective" or "subjective" facts. For instance, on the former approach one might take facts about permissibility to be determined by objective value, while assigning objective disvalue to the running of risks. ${ }^{20}$ On the second approach, one might take facts about permissibility to be determined by the agent's beliefs-or the evidence available to her-regarding objective value. ${ }^{21}$ So there are a range of moral theories able to accommodate the impermissibility of risking wrongdoing-but however this is cashed out, I take Zimmerman to be correct in claiming that it is unconscionable to take certain risks of wronging others.

In certain types of cases, the evidence required for reducing the level of risk to a degree sufficient for eliminating this source of moral prohibition may need to take a certain form. Consider, again, the case of unwanted sex: if engaging in sexual activity absent mental consent* is morally prohibited, then doing so without sufficient evidence of a partner's mental consent ${ }^{*}$ puts her at risk of such

18 For extensive discussion of the significance of risk to our practices of consent, see Bolinger, "Moral Risk and Communicating Consent."

19 Jackson, "Decision-Theoretic Consequentialism and the Nearest and Dearest Objection"; and Zimmerman, "Is Moral Obligation Objective or Subjective?” Sosa, "Consequences of Consequentialism." For discussion, see Zimmerman, "Is Moral Obligation Objective or Subjective?”

21 See, e.g., Jackson, "Decision-Theoretic Consequentialism and the Nearest and Dearest Objection"; and Zimmerman, "Is Moral Obligation Objective or Subjective?" 
wrong and thus is in itself morally prohibited. Plausibly, there will be cases in which such evidence must come in the form of behavioral consent*. Consider again the date between "Grace" and Aziz Ansari: given that they were relative strangers lacking the sort of history and background that would put them in a position to make reliable judgments about each other's mental states, the kind of evidence required to avoid running a prohibitive risk of mental consent ${ }^{*}$ violation would need to come from the other's behavior-that is, their behavioral consent.22 Leaving aside the question of exactly what kind of behavior is required, given the assumption that behavioral consent ${ }^{*}$ in some form can provide the requisite evidence of mental consent*, it can introduce a permission by eliminating an unjustified risk of wrongdoing.

Therefore, like mental consent*, behavioral consent* exhibits the characteristic normative power of consent. It involves agency, manifested through the behavior of the consenter. This behavior is responsive to the consenter's reasons and settled facts in the world-in particular, moral facts, facts about risk, and facts about evidence available to the consentee. It is intentional in the sense of bearing content-the agent's behavior constitutes a signal whose content involves the act behaviorally consented ${ }^{*}$ to. ${ }^{23}$ It is other regarding in that an agent's behavioral consent ${ }^{*}$ alters the duties of another by introducing a permission absent independent overriding reasons. It alters the normative relationship between the consenter and consentee by relieving the latter of a directed duty owed to the former: the duty to refrain from running the risk of wronging them.

I have argued that both mental consent* and behavioral consent* can play the normative role of consent, which entails that this role is not filled uniquely by either. Though I used concrete theories of mental and behavioral consent ${ }^{*}$ for illustration, my argument did not rely on these particular theories. The crucial assumption was, rather, that there is at least one mental state $\psi$ and at least some action $\phi$, such that $B$ wrongs $A$ by performing $\phi$ if $A$ fails to have mental state $\psi$. If this mental state has the additional features of being directed toward $\phi$, it follows that it plays the normative role of consent; adopting this mental state is a content-bearing action/mental state that introduces a permission for its receiver absent independent, overriding sources of impermissibility, thus altering the normative relationship between consenter and consentee. My argument that

22 Some have argued that the requisite evidence in such a case need always be behavioral. See, e.g., Dougherty, "Yes Means Yes" and "Affirmative Consent and Due Diligence"; and Guerrero, "The Epistemology of Consent."

23 Cf. Hurd, "The Moral Magic of Consent"; Archard, Sexual Consent; Wertheimer, Consent to Sexual Relations; Owens, "The Possibility of Consent"; Dougherty, "Sex, Lies, and Consent"; and Alexander, "The Ontology of Consent." 
there is at least some behavior that plays the normative role of consent crucially relied on one additional premise: that running an unjustified risk of wronging someone wrongs them. This entails that $B$ wrongs $A$ by performing $\phi$ if she runs an unjustifiable risk that $A$ fails to have mental state $\psi$. On the plausible assumption that $A$ can perform some behavior that sufficiently lowers this risk, it follows that there is some form of behavior that plays the normative role of consent by introducing a permission in the relevant way.

\section{NON-ESSENTIALITY OF NORMATIVE ROLE}

In the previous section I argued that both mental consent* and behavioral consent $^{*}$ can play the normative role of consent, thus this role is not filled uniquely by any one kind of thing. Here I argue that neither mental consent* nor behavioral consent* ${ }^{*}$ plays this normative role essentially. I demonstrate this by showing that there are contexts in which each of them fails to introduce permissions in the relevant way. Again, I will rely on my working theories for clarity, but the main claim does not rely on these particular conceptions of consent. I consider potential responses in section 4 .

\subsection{Mental Consent ${ }^{*}$ without Behavioral Consent*}

While behavioral consent* is importantly related to mental consent* it is a mistake to suppose - as often happens in the literature on consent - that it is simply an "analogue" of mental consent*, in the sense of being an imperfect stand-in for what is truly morally significant. This is because behavioral consent* transforms the normative landscape through a mechanism that functions independently from mental consent*: the wrong does not involve acting in opposition to an agent's preferences, but rather running an unjustified risk of doing so. So mental consent and behavioral consent* are related in that the latter is conceptually and explanatorily derivative of the former. Behavioral consent ${ }^{*}$ is conceptually derivative of mental consent ${ }^{*}$ in the sense that its analysis is given in terms of mental consent* - specifically, running the risk of its violation. It is explanatorily derivative in the sense that its normative features are explained in terms of the normative features of mental consent ${ }^{* 24}$ However, their normative roles are functional$y$ and metaphysically independent in the sense that the wrong of an instance of behavioral consent* violation need not depend upon the wrong of an instance of mental consent ${ }^{*}$ violation; i.e., an action can be wrong on account of violating behavioral consent ${ }^{*}$ without violating mental consent* Again, consider the context of a sexual encounter between relative strangers: as noted above, because

24 Thanks to David Enoch for this point about explanation. 
participants may lack the sort of history and background that would put them in a position to make reliable judgments about one another's mental states, the kind of evidence required to avoid running a prohibitive risk of mental consent ${ }^{*}$ violation would need to come from the other's behavioral consent ${ }^{* 25}$ In such cases, violating behavioral consent ${ }^{*}$ is morally prohibited, even when mental consent ${ }^{*}$ is not violated. Its moral significance is tied to the impermissibility of running certain kinds of risks, and is not always vitiated when such risks fail to eventuate.

If this is the case, then mental consent ${ }^{*}$ does not play the normative role of consent essentially; there will be cases in which it fails to introduce permissions due to lack of behavioral consent*. Again, this is not contingent upon the particular toy theory of mental consent ${ }^{*}$ I have offered here-it only relies on the assumptions detailed at the end of the last section: as long as (1) there is at least one mental state $\psi$ and at least some action $\phi$, such that $B$ wrongs $A$ by performing $\phi$ if $A$ fails to have mental state $\psi$ and (2) B wrongs $A$ by performing $\phi$ if she runs an unjustifiable risk that $A$ fails to have mental state $\psi$, then mental consent cannot perform the normative role of consent essentially. There will always be the possibility of cases in which $A$ has the requisite mental state, but because $A$ has not signaled with her behavior that she has this mental state, in performing $\phi B$ wrongs her by running the unjustifiable risk that she does not. In such cases, mental consent* fails to introduce a permission in virtue of the absence of behavioral consent*.

\subsection{Behavioral Consent ${ }^{*}$ without Mental Consent*}

Their metaphysical and functional independence similarly entails that behavioral consent ${ }^{*}$ may fail to introduce permissions in cases where mental consent ${ }^{*}$ is absent. If sexual activity can wrong someone when it occurs in opposition to their preferences, then it can do so in spite of misleading evidence regarding those preferences. Recall that we are dealing with two distinct prohibitions: one against violating an agent's mental consent*, the other against running an unjustified risk of doing so. In the case that an agent behaviorally consents*-i.e., signals mental consent ${ }^{*}$ through her outward behavior - then insofar as risk of violating mental consent ${ }^{*}$ is measured by her discernible actions, her partner will not be guilty of unjustifiably running that risk. ${ }^{26}$ But even low risks can eventuate: in the case that an agent fails to mentally consent ${ }^{*}$ to sexual activity, her partner will be guilty of violating her mental consent* even while he has not unjustifiably run

One might argue that the requisite evidence need always be behavioral. I am making the weaker claim that, at least in some cases, acting without behavioral consent is prohibited. 
the risk of doing so. ${ }^{27}$ Depending on the situation, he may not be blameworthy, but he will nevertheless have done wrong (more on this below).

Note, again, that this result does not depend on our working theories of mental and behavioral consent ${ }^{*}$, but rather on the assumption that there is at least one mental state $\psi$ and at least some action $\phi$ such that $B$ wrongs $A$ by performing $\phi$ if $A$ fails to have mental state $\psi$-even if $B$ does has not run an unjustifiable risk of doing so. Nor does it matter how restrictive we make an account of behavioral consent"; as long as it does not entail mental consent there will be cases in which the two come apart. ${ }^{28}$ And as long as some of those cases are such that performing an action without the person's mental consent ${ }^{*}$ wrongs her, the action will be prohibited regardless of the presence of behavioral consent* Therefore, behavioral consent* does not play the normative role of consent essentially; there will be cases in which it fails to introduce permissions due to lack of mental consent*.

\section{RESPONSES}

In this section I survey a number of responses to the arguments given in sections 2 and 3 . First I consider how the mental consent ${ }^{*}$ theorist might deny the claim that behavioral consent ${ }^{*}$ plays the normative role of consent-thus enabling her to reject the corollary claims that this role is not unique or essential to mental consent*. I argue that this move commits the mental consent* theorist to an unpalatable moral theory. Next I consider how the behavioral consent ${ }^{*}$ theorist might deny the claim that mental consent* ${ }^{*}$ plays the normative role of consentthus enabling her to reject the corollary claims that this role is not unique or essential to behavioral consent. I argue that this move leads to an unpalatable theory of consent. Finally, I consider a potential response on behalf of each position: recall that the normative role of consent is being a content-bearing exercise of individual agency that introduces a permission for its receiver absent independent, overriding sources of impermissibility. This qualification leaves room for both the mental consent* theorist and the behavioral consent theorist to file the normative role of the other as one of the "independent" considerations to be bracketed off. I argue that this response is question begging in light of mutually accepted theoretical constraints governing the ontology of consent.

\subsection{Denying the Normative Role of Behavioral Consent*}

The argument that the normative role of consent is nether unique nor essential

27 Following Nagel in "Moral Luck," we might classify this as a case of bad resultant moral luck.

28 For examples and discussion of various "infelicitous" ways that mental consent* and behavioral consent can come apart, see Sherwin, "Infelicitous Sex." 
to mental consent ${ }^{*}$ hinged on the claim that behavioral consent*also plays this normative role; it follows that (1) this role is not unique to mental consent*, and (2) because a behavioral consent ${ }^{*}$ violation can block permissions that would otherwise have been introduced by mental consent*, this role is not essential to mental consent* The mental consent ${ }^{*}$ theorist can resist these conclusions by denying that violating behavioral consent ${ }^{*}$ can constitute a wrong. In this case, behavioral consent* would not play the normative role of consent; it would fail to introduce permissions for the trivial reason that its violation was not prohibited to begin with. And if violation of behavioral consent is not prohibited, then there will not be cases in which such violations block permissions that would otherwise be introduced by mental consent*. Indeed, proponents of the mental consent ${ }^{*}$ view standardly claim that we are incorrect in judging risk-running acts of behavioral consent* violation to be wrong-our sense of wrongdoing is actually tracking the fact that they are culpably performed. ${ }^{29}$ The distinction between wrongdoing and culpability, they argue, is crucial to both legal and moral theorizing. What determines wrongdoing is whether an agent's action violates the dictates of morality; in contrast, certain facts about her mental states in relation to that action - whether she intended to do wrong, could foresee the possibility of doing wrong, etc.- determine her culpability. With this distinction in hand, mental consent ${ }^{*}$ theorists argue that in cases where behavioral consent ${ }^{*}$ is violated but mental consent* has been obtained, agents are "merely culpable" but have done nothing morally impermissible. Considering a hypothetical case of sexual activity between Sam and Sue, Alexander, Hurd, and Westen claim that

if Sam believed there was a significant risk that [Sue] was not [mentally] consenting, then Sam acted culpably. And indeed, such culpability might well be sufficient to justify his being criminally punished, e.g., for attempt. But Sam did not wrong Sue. ${ }^{30}$

The problem with this response is that one may accept the distinction between culpability and wrongdoing without endorsing the verdict that such cases are morally permissible. This is because culpability with respect to one action may imply wrongdoing with respect to another. If the foregoing arguments are correct, there are two related but distinct potential sources of wrongdoing to be considered in the case of sexual activity: (1) wronging someone by violating their mental consent*, and (2) wronging someone by unjustifiably running the risk of doing so. We can accept the culpability/wrongdoing distinction and concede that in such examples Sam is culpable but has done no wrong with respect to (1). How-

See Alexander, Hurd, and Westen, “Consent Does Not Require Communication.”

Alexander, Hurd, and Dougherty, “Consent Does Not Require Communication,” 656. 
ever, if it is indeed the case that unjustifiably putting people at certain kinds of risks is itself wrong, then Sam is not merely culpable, but has violated the dictates of morality with respect to (2). A certain kind of culpability with respect to the former entails wrongdoing with respect to the latter. ${ }^{31}$ Thus, merely invoking the culpability/wrongdoing distinction does not help the mental consent ${ }^{*}$ theorist here; rather, she must deny that placing others at significant and unjustified risk of being wronged is morally prohibited. This is a big bullet to bite; indeed, as discussed in section 2.2, people find it to be so unacceptable that there has been substantial work in tailoring moral theories to be able to accommodate such facts. ${ }^{32}$

Perhaps there is another line of response for the mental consent* theorist, however; she may want to grant that unjustifiably running the risk of wronging someone is morally impermissible, but that it does not constitute a directed wrong. That is, she may want to claim that $B$ acts impermissibly by running an unjustifiable risk of wronging $A$-but that in so doing, $B$ does not wrong $A .{ }^{33}$ Because the normative role of consent involves removing a barrier to permission by relieving the consentee of a directed duty to the consenter, it follows that violating this directed duty is not merely impermissible-it is a wrong that is directed toward the would-be consenter. Thus, if the act of running unjustifiable risks of wronging others does not constitute a directed wrong, then behavioral consent fails to play the normative role of consent-in which case my argument that mental consent* fails to play the normative role of consent uniquely and essentially does not go through.

I want to argue, however, that there are at least some cases in which such risk running violates a directed moral duty, and thus constitutes a directed wrong. I will not take a stand on the "direction problem," i.e., the issue of what grounds the fact that a duty is directed; such a commitment would be beyond the scope of this paper, and the broader argument of this paper should be applicable to a variety of approaches to this issue. Instead, I will appeal to the widely accepted view (perhaps most familiar from Darwall) that directed duties standardly exhibit a certain feature that can be used as a diagnostic test: namely, that when a directed duty toward $B$ has been violated by $A, B$ can legitimately blame $A$ and hold $A$

Just like mere culpability with respect to the crime of murder entails guilt with respect to the crime of attempted murder, we might think that negligence with respect to one action may entail wrongdoing with respect to another.

See, e.g., Jackson, "Decision-Theoretic Consequentialism and the Nearest and Dearest Objection"; and Sosa, "Consequences of Consequentialism." For discussion, see Zimmerman, "Is Moral Obligation Objective or Subjective?"

Thanks to an anonymous reviewer for suggesting this line of response. 
accountable. ${ }^{34}$ This feature is present in cases in which $A$ runs an unjustifiable risk of wronging $B$; for instance, if $A$ wrongs $B$ by running an unjustifiable risk of shooting her in the head (say, by firing a partially loaded gun at her head without knowing which chamber the bullet is in), then $B$ can legitimately blame $A$ and hold her accountable. This feature is also present in the case of sexual activity: $B$ can legitimately blame $A$ and hold her accountable if $A$ unjustifiably runs the risk of violating her mental consent to sex. It is not merely that $A$ violates a general moral duty by running such risks; she violates a directed duty toward $B$. If the moral consent $t^{*}$ theorist accepts that running the risk of doing wrong is at least in some cases a violation of a directed duty, then she must also accept that at least in some cases mental consent ${ }^{*}$ fails to secure permissions; thus, she is forced to deny that mental consent ${ }^{*}$ plays the normative role of consent uniquely and essentially. On the other hand, if she wants to hold on to the commitment to the view that mental consent* plays the normative role of consent uniquely and essentially, she will find herself in the uncomfortable position of being forced to adopt a very strong and controversial broader moral claim about risk.

\subsection{Denying the Normative Role of Mental Consent*}

The argument that the normative role of consent is nether unique nor essential to behavioral consent* worked in roughly the same way; the fact that mental consent* plays this role established that it is not unique to behavioral consent*, and because failure to obtain mental consent ${ }^{*}$ can block permissions that would otherwise have been introduced by behavioral consent*, this role is not essential to behavioral consent*. Again, the behavioral consent* theorist can resist these conclusions by denying that violating mental consent ${ }^{*}$ can constitute a wrong. In this case, mental consent ${ }^{*}$ would not play the normative role of consent; it would fail to introduce permissions for the trivial reason that its violation was not prohibited to begin with. Moreover, if violation of mental consent* is not prohibited, then there will not be cases in which such violations block permissions that would otherwise be introduced by behavioral consent*.

The most plausible way to deny that violating mental consent* constitutes a wrongdoing is to adopt an agent-relative moral theory. One might claim with Frank Jackson, for instance, that facts about permissibility are determined by the mental states of the agent performing the act in question (here, the would-be consentee, rather than consenter) — such as her subjective probabilities about moral value. To illustrate, let us consider the case of Grace and Ansari: someone with this

34 Darwall, The Second-Person Standpoint. See also Mill, Utilitarianism, ch. 5; Brandt, A Theory of the Good and the Right, 163-76; Gibbard, "Wise Choices, Apt Feelings," 41; and Wallace, "Reasons, Relations, and Commands," 29. 
view on permissibility might claim that though violating Grace's preferences regarding their sexual activity had moral disvalue, in doing so Ansari did not wrong her (assuming-implausibly, in my view — that his subjective probability that he was violating her mental consent* was sufficiently low). This is because the facts about permissibility are not simply determined by facts about moral value, but rather by facts about moral agents' subjective probabilities about such value. Thus, whether or not Ansari wronged Grace is determined by his subjective probability concerning whether she mentally consented*, not whether she in fact did so.

This kind of approach to moral permissibility is subject to objections that issues of consent bring out particularly well: there are different ways of understanding the claim that permissibility is determined by an agent's subjective probabilities regarding the moral value of her actions. If we take her subjective probabilities to be determined by her beliefs, it follows that any case of unwanted sex is permissible so long as the agent believes that the other party prefers it, regardless of how irrational or unjustified this belief might be. Moreover, contexts of sexual activity raise the particular problem that participants may fail to take heed of evidence in forming their beliefs because of bigoted attitudes, or because they would benefit from ignoring it. Participants in the public debate on the Ansari scandal have made this point in numerous ways:

[Men] think everything is fine because they want it to be. For them, it's best when it's or because that "oK" gets them what they want. ${ }^{35}$

If your view of women is that they are not really human beings, you're going to have a problem hearing what they say when you're determined to have sex with them. ${ }^{36}$

These kinds of results can be avoided by taking a more "objective" view of subjective probability - rather than being determined by the agent's beliefs, we take them to be determined by the evidence available to her regarding the moral value of her potential actions. But again, there are problems with this view that are brought out particularly well by thinking about issues of consent. As Zimmerman points out, if permissibility is determined by the evidence one has on hand about the moral value of one's potential actions, then one is not obliged to seek out more information about those facts. But in cases of risk-for instance, the risk of violating another's bodily integrity—it seems clear that agents are obliged to seek out more information rather than acting on the evidence available to them at the time. 
Moreover, there is another more general problem with this approach, which is that the conception of consent it delivers fails to satisfy the normative role of consent. Recall that consent's normative role is being a manifestation of the consenter's agency that can introduce permissions (for the consentee) absent independent overriding considerations. If we take facts about what is permissible for the consenter to be determined by facts about her own mental states or evidence, this implies that it is not-strictly speaking — the consenter who alters those permissions. Granted, the consenter can perform some behavior that has the contingent causal effect of altering the mental states and evidence of the consentee. Nonetheless, her action is ultimately not playing a metaphysically robust role in altering the normative landscape-while her behavior may have some contingent, causal influence over the consentee's mental states and total body of evidence, it is the latter and not the former that metaphysically determines what is permissible for him. The consenter, in this case, has no power to settle the fact of the matter about what is permissible for the consentee; she may have some causal influence over this, but the matter is ultimately settled by facts about the consentee's mental states. Thus, the change in the normative landscape is not a manifestation of the consenter's agency. This implies that there is nothing that plays the normative role of consent, given that it metaphysically divorces facts about what is permissible for the consentee from the agency of the consenter. Thus the behavioral consent ${ }^{*}$ theorist will have a difficult time denying the impermissibility of violating mental consent ${ }^{*}$ without committing herself to an implausible view of consent-or abandoning the notion altogether.

\subsection{Appealing to Independent Reasons}

I have claimed that in order to resist the argument that the normative role of consent is not essential or unique to mental consent*, the behavioral consent theorist must deny that the violation of mental consent ${ }^{*}$ can constitute a wrong (and vice versa). I have argued, however that the behavioral consent* theorist cannot deny that violating mental consent ${ }^{*}$ is impermissible without committing herself to an unpalatable theory of consent, and that the mental consent ${ }^{*}$ theorist cannot deny that violating of behavioral consent ${ }^{*}$ is impermissible without committing herself to an unpalatable moral theory. There is a second option for both positions, however: each can accept that the violation of the other may constitute a wrong, but deny that this wrong is consent related. Instead, they can characterize that wrong as one of the "independent" moral considerations bracketed off by the definition of the normative role of consent.

The characteristic normative power of consent is not limitless; we expect there to be limitations on this power, and so the fact that any particular theo- 
ry of consent predicts such limitations will be a virtue rather than a drawback of that theory. The idea is that there are certain actions such that lack of consent provides a certain kind of pro tanto moral reason against performing them. Absent overriding reasons in favor of performing such actions, lack of consent renders them impermissible; when consent is obtained, this particular source of prohibition is eliminated. But, of course, there may be independent moral reasons that count against performing the action-and because consent's power to transform prohibitions into permissions is a function of eliminating only certain sources of prohibition (those generated by lack of consent), we should expect it to be limited to cases in which there are not independent, overriding sources of prohibition. For instance, an act of adultery may be consensual but nonetheless morally prohibited because of the harm it would cause a third party. Our characterization of the normative role of consent brackets off such cases: we have said that consent is a content-bearing act of individual agency that introduces a permission for its receiver absent independent overriding considerations. This opens the door for a flatfooted way for both the mental consent ${ }^{*}$ theorist and the behavioral consent ${ }^{*}$ theorist to respond to the arguments above; each may claim that the source of the prohibition identified by the other is independent rather than consent related. For instance, some mental consent* theorists have noted that violation of behavioral consent ${ }^{*}$ may constitute an "independent" act of wrongdoing; Ferzan, e.g., does not characterize it as risk running, as I have, but rather an act of disrespect. ${ }^{37} \mathrm{~A}$ behavioral consent ${ }^{*}$ theorist could, in turn, acknowledge that violating mental consent ${ }^{*}$ is in some cases wrong, but characterize this wrongdoing as independent and non-consent related.

There are two problems with this response. The first is that while it gets around the non-essentiality counterexamples, it does not get around the non-uniqueness counterexamples. I argued above neither mental consent* nor behavioral consent ${ }^{*}$ plays the normative role of consent essentially, given that (1) there are contexts in which mental consent ${ }^{*}$ fails to introduce permissions in the absence of behavioral consent ${ }^{*}$, and (2) there are contexts in which behavioral consent* fails to introduce permissions in the absence of mental consent* The mental consent ${ }^{*}$ theorist can resist the claim that mental consent ${ }^{*}$ fails to display the normative role essentially by suggesting that absence of behavioral consent* merely introduces an independent source of prohibition, and vice versa. While this response allows each theorist to insist that her conception of consent plays the normative role of consent essentially, it does not provide her with a way to claim that it does so uniquely; there will still be cases in which both mental con- 
sent ${ }^{*}$ and behavioral consent ${ }^{*}$ function to eliminate prohibitions in the particular way that is characteristic of consent.

The second problem with this response is that, in the context of the debate over the ontology of consent, to simply stipulate that the opposing conception of consent is an independent and non-consent-related moral consideration is to flatly beg the question at hand. Neither conception seems to respond better to our ordinary, pre-theoretical conception of consent (as evidenced by the debates in the literature and in the public sphere) - a fact that is readily acknowledged by theorists on both sides, who often cede that use of the word "consent" is polysemous between various readings. The same has been shown to be true in legal contexts. ${ }^{38}$ Moreover, both conceptions are equally relevant to evaluating moral behavior, often in the very same cases - tellingly, those in which we take consent to be morally relevant. The point is not merely that both conceptions have moral weight in such situations, but that in both cases their normative role functions in the peculiar way that we have pre-theoretically characterized as belonging to consent: they both involve manifestations of individual agency directed toward the act in question, and they both introduce permissions for the consentee absent overriding considerations. Given that fit with this role is used to adjudicate between competing ontologies of consent, and given that both mental consent* and behavioral consent* fit it equally well, simply stipulating that the opposing conception is not really consent is a question-begging response to counterexamples to one's preferred theory.

\section{PROBLEMS WITH A HYBRID APPROACH}

A natural response would be to adopt a hybrid view, in which an act of consent is taken to require both mental consent* and behavioral consent ${ }^{*}{ }^{39}$ This seems to address the worry that neither mental consent ${ }^{*}$ nor behavioral consent ${ }^{*}$ is sufficient on its own to introduce relevant permissions in every context. On this approach, consent is usually characterized as a type of action that necessarily has a mental component-for instance, it is common to claim that consent is an action performed intentionally. ${ }^{40}$ The problem with the hybrid view is that it

See Westen, The Logic of Consent; and Dougherty, "Affirmative Consent and Due Diligence." See Dougherty, "Yes Means Yes."

See, e.g., Owens, "The Possibility of Consent”; Archard, Sexual Consent; Dougherty, "Yes Means Yes"; and Wertheimer, Consent to Sexual Relations. Other views that are sometimes categorized under the heading of "hybrid" treat consent as a type of action but add the qualification that a certain kind of mental state may be needed in order for it to be morally transformative. See Miller and Wertheimer, "Preface." 
collapses the structure behind the mechanism that gives consent its normative power; the reason that consent is able to change prohibitions into permissions is not because mental states and behavior combine to produce a mechanism that generates this power. Rather, there are two independent mechanisms, each exhibiting the normative power of consent when taken individually. Mental consent ${ }^{*}$ has this power because it is prohibited to wrong others, and mental consent ${ }^{*}$ can change the facts about whether an action will wrong a person. In contrast, behavioral consent ${ }^{*}$ has this power because it is prohibited to put others at risk of being wronged, and behavioral consent ${ }^{*}$ can change facts about risk. Their combination does not create a new moral reason, as it were, but merely aggregates the weight of two independent moral reasons. In treating consent as a unified phenomenon, the hybrid view threatens to mask the complexity behind consent's normative power.

A second and related problem is that the hybrid view is too strong: the conjunction of mental consent ${ }^{*}$ and behavioral consent ${ }^{*}$ is not necessary for changing prohibitions into permissions. ${ }^{41}$ As mental consent ${ }^{*}$ theorists have repeatedly pointed out, there are cases in which behavioral consent ${ }^{*}$ is not necessary to change prohibitions into permissions, because mental consent*alone is sufficient. These are cases in which the risk of violating mental consent ${ }^{*}$ is sufficiently low; in such cases, acting without behavioral consent ${ }^{*}$ does not constitute running a prohibitively high risk of wronging another. Consider, for instance, the following scenario: Mona and Lisa are long-term partners with an active and trusting sexual relationship. One morning Lisa sleeps through her alarm clock, and so Mona wakes her up with a kiss, an act that Lisa mentally consents* to. ${ }^{42}$ Though Mona did not obtain behavioral consent ${ }^{*}$ from Lisa before performing this action, their history together provided her with sufficient evidence that Lisa would mentally consent* to it; the fact that she did not obtain behavioral consent ${ }^{*}$ did not amount to unjustifiably running a risk of wronging her. ${ }^{43}$ Since Lisa did in fact mentally consent*, Mona did not wrong her in performing this action-neither by violating her preferences nor by running an unjustifiably high

Bolinger's version of a hybrid account is disjunctive rather than conjunctive ("Moral Risk and Communicating Consent"). This makes the view too weak (in the sense of being susceptible to the non-essentiality arguments of the last section) rather than too strong.

I assume that people can have preferences and other mental states while sleeping. Alternatively, we can imagine that Lisa is merely pretending to be asleep.

43

One might respond that Mona obtained behavioral consent from Lisa, given Lisa's past behavioral cues. But, as campus campaigns for active, ongoing consent bring out, such a notion of consent is problematic; contexts and preferences are constantly in flux, and for an agent $A$ to consent to sexual activity with another agent $B$ at one time and context does not amount to her consenting to sexual activity with $B$ at all future times and contexts. 
risk of doing so. Mental consent*, in this case, was sufficient to transform what would have otherwise been a prohibited act into a permissible one. The hybrid view gets such cases wrong by demanding the presence of behavioral and mental consent ${ }^{*}$ in every context. ${ }^{44}$

\section{CONCLUSION}

The guiding methodology in developing an ontology of consent has been to identify the kind of thing that plays its normative role - that is, the kind of thing that is a content-bearing manifestation of individual agency that introduces a permission for another absent independent, overriding circumstances, thus altering the normative relationship between consenter and consentee. I have argued that we ought to reject a tacit assumption underling the debate over the ontology of consent-which is that there is a single kind of thing that does this essentially or uniquely. Both mental consent* and behavioral consent ${ }^{*}$ play this role in certain contexts, through different mechanisms; moreover, neither is sufficient on its own to play this role in every context. Recognizing this, we can see how the tacit assumption that consent is a unary kind has led to an impasse in the literature on the ontology of consent: not only is the ordinary conception of consent ambiguous between mental and behavioral consent ${ }^{*}$, but they both play its normative role-often in the very same contexts. This has forced both parties to the debate to dig in their heels and adopt question-begging responses to the counterexamples presented by the other. Though theoretical unity may be preferable, all things being equal, I have argued that all things are not equal; the considerations presented above suggest that we ought to reject the assumption that consent is a unary phenomenon and adopt a pluralistic approach. ${ }^{45}$ Because mental states and behaviors introduce different kinds of pro-tanto permissionseach of which can be overridden by lack of the other-it is necessary to weigh each of their independent moral contributions in order to understand how consent functions to alter permissions across disparate contexts. ${ }^{46}$

\section{University of Leeds keiserjessicalynn@gmail.com}

44 It is less clear to me that behavioral consent can transform prohibitions into permissions absent mental consent. But all that is needed to show that the hybrid view is too strong is that there are cases in which at least one conjunct is not necessary. Thanks to David Enoch for pushing me to acknowledge the value of theoretical unity. feedback on written drafts, and to the audience at the Cornell Philosophy of Law confer- 


\section{REFERENCES}

Alexander, Larry. “The Moral Magic of Consent (II)." Legal Theory 2, no. 3 (September 1996): 165-74.

—. "The Ontology of Consent." Analytic Philosophy 55, no. 1 (March 2014): 102-13.

Alexander, Larry, Heidi Hurd, and Peter Westen. "Consent Does Not Require Communication: A Reply to Dougherty." Law and Philosophy 35, no. 6 (December 2016): 655-60.

Anderson, Michelle J. “All-American Rape.” St. John's Law Review 79, no. 3 (Summer 2005): 625-44.

- Sexual Consent. Boulder: Westview Press, 1998.

Beran, Harry. The Consent Theory of Political Obligation. London: Croom Helm, 1987.

Bolinger, Renée Jorgensen. "Moral Risk and Communicating Consent." Philosophy and Public Affairs 47, no. 2 (Spring 2019): 179-207.

Brandt, Richard. A Theory of the Good and the Right. Oxford: Oxford University Press, 1979.

Darwall, Stephen. The Second-Person Standpoint: Morality, Respect, and Accountability. Cambridge, MA: Harvard University Press, 2006.

Dougherty, Tom. "Affirmative Consent and Due Diligence." Philosophy and Public Affairs 46, no. 1 (Winter 2018): 90-112.

—. "Fickle Consent." Philosophical Studies 167, no. 1 (January 2014): 25-40. ."Sex, Lies, and Consent." Ethics 123, no. 4 (2013): 717-44.

- "Yes Means Yes: Consent as Communication." Philosophy and Public Affairs 43, no. 3 (2015): 224-53.

Estlund, David M. Democratic Authority: A Philosophical Framework. Princeton: Princeton University Press, 2008.

Faden, Ruth R., and Tom L. Beauchamp. A History and Theory of Informed Consent. New York: Oxford University Press, 1986.

Ferzan, Kimberly. "Consent, Culpability, and the Law of Rape." Ohio State Journal of Criminal Law 13, no. 2 (2016): 397-439.

Gibbard, Allan. “Wise Choices, Apt Feelings." Cambridge, MA: Harvard University Press, 1990.

Guerrero, Alexander A. “The Epistemology of Consent." In Applied Epistemology, edited by Jennifer Lackey. Oxford: Oxford University Press, forthcoming. Hobbes, Thomas. Leviathan. 1651. In Early Modern Philosophy: Essential Read- 
ings with Commentary, edited by A. P. Martinich, Fritz Allhoff, and Anand Jayprakash Vaidya, 61-69. Hoboken, NJ: Blackwell, 2006.

Hurd, Heidi M. “The Moral Magic of Consent." Legal Theory 2, no. 2 (June 1996): 121-46.

Jackson, Frank. "Decision-Theoretic Consequentialism and the Nearest and Dearest Objection.” Ethics 101, no. 3 (April 1991): 461-82.

King, Kristen. "Aziz Ansari Allegations Show that People Have a Lot to Learn about Consent." Teen Vogue, January 16, 2018. https://www.teenvogue.com/ story/aziz-ansari-consent-op-ed.

Kleinig, John. "The Nature of Consent." In Miller and Wertheimer, The Ethics of Consent, 3-24.

Locke, John. The Two Treatises of Civil Government. 1689.

MacKinnon, Catharine A. Toward a Feminist Theory of the State. Cambridge, MA: Harvard University Press, 1991.

Manson, Neil C. "Permissive Consent: A Robust Reason-Changing Account." Philosophical Studies 173, no. 12 (December 2016): 3317-34.

Manson, Neil C., and Onora O’Neill. Rethinking Informed Consent in Bioethics. Cambridge: Cambridge University Press, 2007.

Mill, John Stuart. Utilitarianism. Edited by Roger Crisp. Oxford: Oxford University Press, 1998.

Miller, Franklin G., and Alan Wertheimer, eds. The Ethics of Consent: Theory and Practice. Oxford: Oxford University Press, 2010.

- "Preface." In Miller and Wertheimer, The Ethics of Consent, ix.

Nagel, Thomas. "Moral Luck.” In Moral Luck, edited by Daniel Statman 141-66. Albany, NY: State University of New York Press, 1993.

Owens, David. "The Possibility of Consent." Ratio 24, no. 4 (December 2011): 402-21.

Pateman, Carole. "Women and Consent." Political Theory 8, no. 2 (May 1980): 149-68.

Reilly, Natalie. "Aziz Ansari and the Issue of Consent." Sydney Morning Herald, January 15, 2018. https://www.smh.com.au/entertainment/celebrity/why -im-not-surprised-by-aziz-ansari-allegations-20180115-hoig2c.html.

Schulhofer, Stephen J. "The Feminist Challenge in Criminal Law." University of Pennsylvania Law Review 143 (1995): 2151-2207.

Sherwin, Emily. "Infelicitous Sex." Legal Theory 2, no. 3 (September 1996): 20931.

Shiffrin, Seana Valentine. "Promising, Intimate Relationships, and Conventionalism." Philosophical Review 117, no. 4 (October 2008): 481-524. 
Sosa, David. "Consequences of Consequentialism." Mind 102, no. 405 (January 1993): 101-22.

Steward, Helen. A Metaphysics for Freedom. Oxford: Oxford University Press, 2012.

Wallace, R. Jay. "Reasons, Relations, and Commands: Reflections on Darwall." Ethics 118, no. 1 (October 2007): 24-36.

Wertheimer, Alan. Consent to Sexual Relations. Cambridge: Cambridge University Press, 2003.

West, Robin. "Sex, Law, and Consent." In Miller and Wertheimer, The Ethics of Consent, 221-50.

Westen, Peter. The Logic of Consent: The Diversity and Deceptiveness of Consent as a Defense to Criminal Conduct. Farnham, Uk: Ashgate, 2004.

Zimmerman, Michael J. "Is Moral Obligation Objective or Subjective?" Utilitas 18, no. 4 (December 2006): 329-61. 